BMJ Open

Sport \&

Exercise

Medicine

\title{
Are parents' motivations to exercise and intention to engage in regular family- based activity associated with both adult and child physical activity?
}

\author{
Emma Solomon-Moore, ${ }^{1}$ Simon J Sebire, ${ }^{1}$ Janice L Thompson, ${ }^{2}$ Jesmond Zahra, ${ }^{1}$ \\ Debbie A Lawlor, ${ }^{3,4}$ Russ Jago ${ }^{1}$
}

\section{ABSTRACT}

Background/aim: To examine the associations between parents' motivation to exercise and intention to engage in family-based activity with their own and their child's physical activity.

Methods: Cross-sectional data from 1067 parentchild pairs $(76.1 \%$ mother-child); children were aged 5-6 years. Parents reported their exercise motivation (ie, intrinsic motivation, identified regulation, introjected regulation, external regulation and amotivation) as described in self-determination theory and their intention to engage in family-based activity. Parents' and children's mean minutes of moderate-tovigorous-intensity physical activity (MVPA) and mean counts per minute were derived from ActiGraph accelerometers worn for 3 to 5 days (including a mixture of weekdays and weekend days). Multivariable linear regression models, adjusted for parent sex, number of children, indices of multiple deprivation and clustering of children in schools were used to examine associations (total of 24 associations tested).

Results: In fully adjusted models, each unit increase in identified regulation was associated with a 6.08 $(95 \% \mathrm{Cl} 3.27$ to $8.89, \mathrm{p}<0.001)$ min-per-day increase in parents' MVPA. Parents' external regulation was associated with children performing $2.93(95 \% \mathrm{Cl}$ -5.83 to $-0.03, p=0.05$ ) fewer minutes of MVPA per day and a $29.3(95 \% \mathrm{Cl}-53.8$ to $-4.7, \mathrm{p}=0.02)$ accelerometer count-per-minute reduction. There was no evidence of association for the other 21 associations tested.

Conclusions: Future family-based physical activity interventions may benefit from helping parents identify personal value in exercise while avoiding the use of external control or coercion to motivate behaviour.

\section{INTRODUCTION}

Physical inactivity is estimated to cause 6\% of deaths globally, making it the fourth leading risk factor for global mortality. ${ }^{1}$ In England, $67 \%$ of men and $55 \%$ of women self-reported meeting the recommended guidelines of at least 150 min of moderateintensity or $75 \mathrm{~min}$ of vigorous-intensity

\section{What are the new findings?}

- Parents of young children who accept exercise as personally important or valuable to them engage in six more minutes of physical activity per day.

- Young children whose parents exercise because of external demands or possible reward engage in almost three less minutes of physical activity per day.

- Future family-based physical activity interventions should focus on increasing parents' autonomous motivation to exercise and avoid using external controls or coercion to motivate behaviour.

activity per week. ${ }^{2}$ However, when physical activity (PA) was measured objectively using accelerometers, only $6 \%$ of men and $4 \%$ of women met the guidelines. ${ }^{3}$ For children aged $5-15$ years, only $33 \%$ of boys and $21 \%$ of girls met the recommended guidelines $(\geq 1$ hour per day of moderate-intensity PA). ${ }^{3}$

\section{Families and PA}

Due to the low prevalence of sufficient PA among the population, targeting families may be an important way to increase PA among children and their parents. However, the majority of research concerning the psychosocial determinants of PA has focused on the general adult population, ${ }^{4}$ relying on the assumption that the factors that affect PA are the same for parents and non-parents. Emerging evidence, however, suggests otherwise. The onset of parenthood has been associated with a decline in $\mathrm{PA},{ }^{5}{ }^{6}$ and parents of young children report having fewer opportunities for PA because they have new responsibilities and time commitments, ${ }^{7-10}$ 
and their priorities have shifted from themselves to their child. ${ }^{11}$

The best available data suggest that the association between parent and child PA is weak. ${ }^{12} 13$

Parents are, however, an important influence on their children's $\mathrm{PA}^{14-16}$ through the extent to which a parent facilitates PA for their child and parental attitudes towards PA. ${ }^{15}$ Collectively, the research suggests that parents do not have to be active themselves to influence their child's $\mathrm{PA},{ }^{17}$ but that more research is needed to understand how parents influence their children's PA.

\section{Exercise motivation}

Motivation to exercise is central to understanding adults' PA. $^{18}$ Self-determination theory (SDT) is a conceptual framework in which motivation for a given behaviour (eg, PA) is broadly classified as either autonomous or controlled and that these characteristics can either facilitate or hinder behavioural performance and persistence. ${ }^{19}$ Autonomous types of motivation comprise intrinsic motivation (ie, doing a behaviour for its inherent satisfaction/enjoyment), integrated regulation (ie, where performing a behaviour is aligned with one's identity) and identified regulation (ie, consciously valuing a behaviour). ${ }^{20}$ In contrast, controlled motivation represents less self-determined reasons for behaviour, and comprises introjected regulation (ie, doing something in order to protect one's ego or to avoid guilt) and external regulation (ie, performing behaviours to satisfy external demands or obtain rewards). While autonomous and controlled motivation vary in their self-determination, amotivation is the lack of motivation to perform a certain behaviour. ${ }^{20}$ Good evidence has been demonstrated for the value of SDT in understanding and promoting exercise behaviour. ${ }^{21}$ Specifically, adults' autonomous motivation has been found to be positively associated with objectively assessed PA, whereas controlled motivation has not. ${ }^{22}{ }^{23}$ However, a systematic review identified several studies in which introjected regulation was positively associated with $\mathrm{PA},{ }^{21}$ highlighting the complex nature of the motivation-behaviour relationship. ${ }^{24-26}$ When these studies were examined closely, the strength of association for introjected regulation was lower compared with autonomous types of motivation. ${ }^{21} 2426$

Parents of young children arguably experience more challenges to converting PA motivation into behaviour than non-parents because of the greater demands on their time and PA being less of a priority. It is important to understand what types of motivation are associated with PA in parents, as opposed to adults in general, and whether autonomous motivation is enough to bridge the motivation-PA gap for busy parents. It is also possible that the quality of parents' exercise motivation (eg, autonomous vs controlled) could influence their child's PA. For example, if parents' motivations are primarily controlled and they feel PA is something that they 'have to' rather than 'want to' do, when faced with the demands of parenting a young child they may not: (1) authentically engage in PA themselves or (2) have strong intentions to promote PA with their child. A cross-sectional study of parents with young children found parents' self-determined motivation was indirectly associated with their intention to be active via their attitudes. ${ }^{27}$ However, the motivation variable only represented identified regulation, PA was self-reported, child PA was not measured, and while parents' intentions were measured, their intention to be active with their child was not. Additionally, previous work has integrated the SDT motivation constructs with the concept of intention. ${ }^{27}$ ${ }^{28}$ In undergraduate students, autonomous motivation was positively associated with intention, which was in turn associated with exercise behaviour, whereas the associations between controlled motivation, intention and behaviour were relatively modest in comparison, albeit still positive. ${ }^{29}$ To date, no research has explored the association between parents' autonomous and controlled motivation, their intention to engage in family-based activity and their own and their child's objectively assessed PA. Further, no research has examined whether intention mediates the motivationbehaviour association. Thus, this study will advance SDT-based research by improving our understanding of the association between motivation and PA within the context of parenthood.

The aim of this research was to examine the associations between parents' motivation to exercise and their own and their young child's objectively assessed PA, and whether these associations were mediated by parents' intention to engage in regular family-based activity. It is hypothesised that parents' autonomous motivation regulations and intention to engage in family-based activity will be positively associated with PA for both parents and children, while parents' controlled motivation regulations will be negatively associated with PA.

\section{METHODS}

\section{Sampling}

The current analyses used data from a cross-sectional study (B-ProActlv) carried out at the University of Bristol. The study aimed to identify factors associated with young children's (5-6 years) and parents' PA and screen viewing, with a specific focus on the influence of parents on child PA and screen-viewing behaviours. Study design, participant recruitment and data collection methods are described in greater detail elsewhere, ${ }^{12}$ and several papers have been published from the data. ${ }^{12}$ 30-34 Briefly, in 2012-2013, data were collected from 57 primary schools in the greater Bristol area, from 250 schools approached (22.8\%). Written informed consent was obtained from parents for both the parents' and children's participation. ${ }^{35}$ 
Ethical approval was granted by the School for Policy Studies research ethics committee at the University of Bristol. In total, 1456 child-parent dyads consented to take part. Child-parent dyads of 1267 wore and returned an accelerometer and were included in the final dataset. For the current study, we were interested in parents' exercise motivations, therefore, results herein are based on data for the 1067 child-parent dyads that provided accelerometer data and completed at least part of the motivation measures. Figure 1 shows the study flow of participants.

\section{Data collection}

Parents were asked to complete a questionnaire about family characteristics, personal demographics, exercise motivations and intention to engage in regular familybased PA. Parents self-reported their sex, height and weight to enable the calculation of body mass index $\left(\mathrm{BMI}=\mathrm{kg} / \mathrm{m}^{2}\right.$ ). Indices of Multiple Deprivation (IMD) scores, based upon the English Indices of Deprivation (http://data.gov.uk/dataset/index-of-multiple-deprivation), were assigned to each dyad based on their self- reported home postcode, where higher IMD scores indicate a greater level of local deprivation.

\section{Physical activity}

Children and parents wore an ActiGraph GT3X accelerometer on their waist for 5 days, 3 weekdays and 2 weekend days. ActiGraph GT3X accelerometers have been demonstrated to have good validity for measuring PA in free-living conditions, ${ }^{36} 37$ and waist-worn accelerometers have been demonstrated to outperform wrist-worn accelerometers during laboratory-based step counts. ${ }^{38}$ Parents and children were included in the primary analyses if they provided at least 3 days of valid data (including at least 1 weekend day) to conform with the method used in previous studies. ${ }^{12} \mathrm{~A}$ valid day was defined as $\geq 500 \mathrm{~min}$ of data, after excluding intervals of $\geq 60 \mathrm{~min}$ of zero counts allowing up to 2 min of interruptions. ${ }^{39}$ Uniaxial data were processed using Kinesoft software (V.3.3.75; Kinesoft, Saskatchewan, Canada). Minutes spent in moderate-tovigorous-intensity physical activity (MVPA) were derived using population-specific cut points for children and adults. ${ }^{40}$ Mean accelerometer counts per

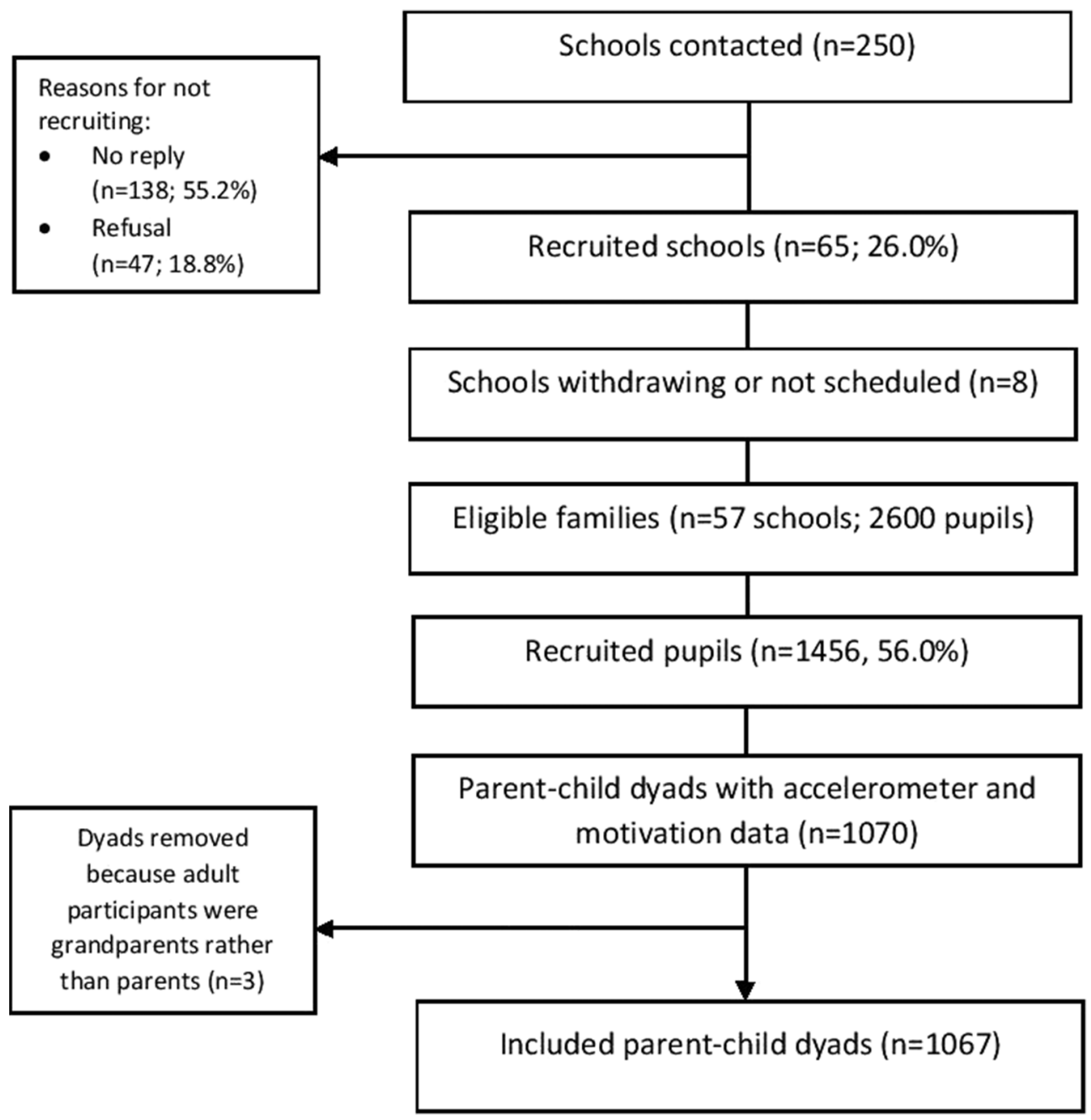

Figure 1 Study flow of participants. 
minute (CPM) were calculated to provide an indication of volume of PA.

\section{Motivation and intention}

Parents' motivation to exercise was measured using the 19-item Behavioural Regulation in Exercise Questionnaire (BREQ-2). ${ }^{42}$ The BREQ-2 assesses five forms of exercise motivation regulations: intrinsic, identified, introjected, external and amotivation. Participants rated each item on a 5-point Likert scale ranging from 0 (not true for me) to 4 (very true for $m e$ ). In the current study, the internal consistency of the BREQ-2 subscales was: intrinsic $(\alpha=0.92)$, identified $(\alpha=0.83)$, introjected $(\alpha=0.75)$, external $\quad(\alpha=0.70)$ and amotivation $(\alpha=0.76)$.

Intention to regularly engage in family-based PA was measured using a single-item scale adapted from previous research. ${ }^{43}$ Participants responded to the stem 'Thinking about the upcoming month, indicate how many times per week you are intending to engage in regular family-based physical activity' with an open answer. The range of acceptable scores was 0 to $\geq 7$ (ie, eight categories).

\section{Statistical analysis}

The six independent variables (five motivation scores and one intention score) were treated as continuous variables. Spearman's correlations were used to explore associations between variables. $\chi^{2}$ tests and $\mathrm{t}$ tests were conducted to examine the differences between included and excluded participants. Multivariable linear regression models were used to examine associations between the six independent variables with mean MVPA minutes per day and accelerometer CPM for parents and children (ie, a total of 24 associations: six independent variables with two outcomes in two groups (parent and child). Each model was adjusted for parent sex, number of children in the household and IMD score as these have been previously associated with PA in adults. ${ }^{6} 18{ }^{45}$ Robust standard errors were used to take account for clustering of children within schools. When designing this paper, we intended to conduct mediation analysis of parent exercise motivation on parent and child MVPA via intention to engage in family-based activity. However, as no associations were found between intentions and either parent or child MVPA, mediation analysis could not be conducted. All analyses were performed in Stata V.12.0. ${ }^{46}$

\section{RESULTS}

\section{Descriptive characteristics}

Descriptive characteristics of the study sample have been reported previously. ${ }^{12}$ Correlation results are presented in table 1. Generally, parents were female (76.1\%), with an average two children per household, were autonomously motivated to exercise and expressed intention to engage in regular family-based activity at least three times per week. The mean IMD score fell within the middle quintile, however a greater proportion of families were in the two least deprived quintiles $(40.4 \%$ and $23.8 \%)$, compared with the middle quintile $(15.7 \%)$ and the two most deprived quintiles (10.9\% and 9.3\%). The average daily time spent in MVPA exceeded the recommended guidelines for adults (mean (SD); 49.7 (24.8) min) and children (67.6 (20.7) min). ${ }^{47}$ Mean child age was 6.01 (SD: 0.42) years, and mean parent age was 37.75 (SD: 5.68 years). Included participants were generally similar to participants who were excluded due to missing data (table 2). However, excluded participants were more likely to be female $(p=0.03)$, with less children $(p=0.02)$, more deprived $(\mathrm{p}<0.001)$, higher amotivation $(\mathrm{p}<0.001)$ and external regulation $(\mathrm{p}=0.04)$, and lower identified regulation $(\mathrm{p}<0.001)$ and intrinsic motivation $(\mathrm{p}<0.001)$.

\section{Parents' physical activity}

There was strong evidence, in the unadjusted models, that amotivation was negatively associated with parents' MVPA $(b:-5.53,95 \% \mathrm{CI}:-8.30$ to $-2.75, \mathrm{p}<0.001)$, while introjected regulation $(2.53,1.06$ to 3.99 , $\mathrm{p}=0.001)$, identified regulation $(5.76,4.28$ to 7.25 , $\mathrm{p}<0.001)$ and intrinsic motivation $(4.44,3.10$ to 5.78 , $\mathrm{p}<0.001$ ) were positively associated with MVPA (table 3). There was also evidence that parents' intention to engage in regular family-based activity was positively but weakly associated with MVPA $(0.91,0.16$ to 1.67 , $\mathrm{p}=0.02)$. In the fully adjusted models $\left(\mathrm{R}^{2}=0.14\right)$, every one-unit increase in identified regulation was associated with 6.08 (3.27 to $8.89, \mathrm{p}<0.001)$ min-per day greater MVPA for parents.

\section{Child's physical activity}

For child MVPA, there was evidence in the unadjusted models that both parents' identified regulation (1.51, 0.28 to $2.74, \mathrm{p}=0.02)$ and intrinsic motivation (1.27, 0.17 to $2.36, \mathrm{p}=0.02$ ) were positively associated with MVPA (table 4). In the fully adjusted models $\left(\mathrm{R}^{2}=0.18\right)$, there was weak evidence that parents' external regulation was associated with a $2.93(-5.83$ to $-0.03, \mathrm{p}=0.05)$ min-per-day reduction in children's MVPA.

\section{Accelerometer CPM}

No associations were found between motivation or intention and accelerometer CPM for parents in either the unadjusted or fully adjusted models (table 5). Parents' external regulation was associated with a 29.3 $(-53.8$ to $-4.7, \mathrm{p}=0.02)$ CPM reduction in children's PA in the fully adjusted model $\left(R^{2}=0.20\right.$; table 6$)$. 


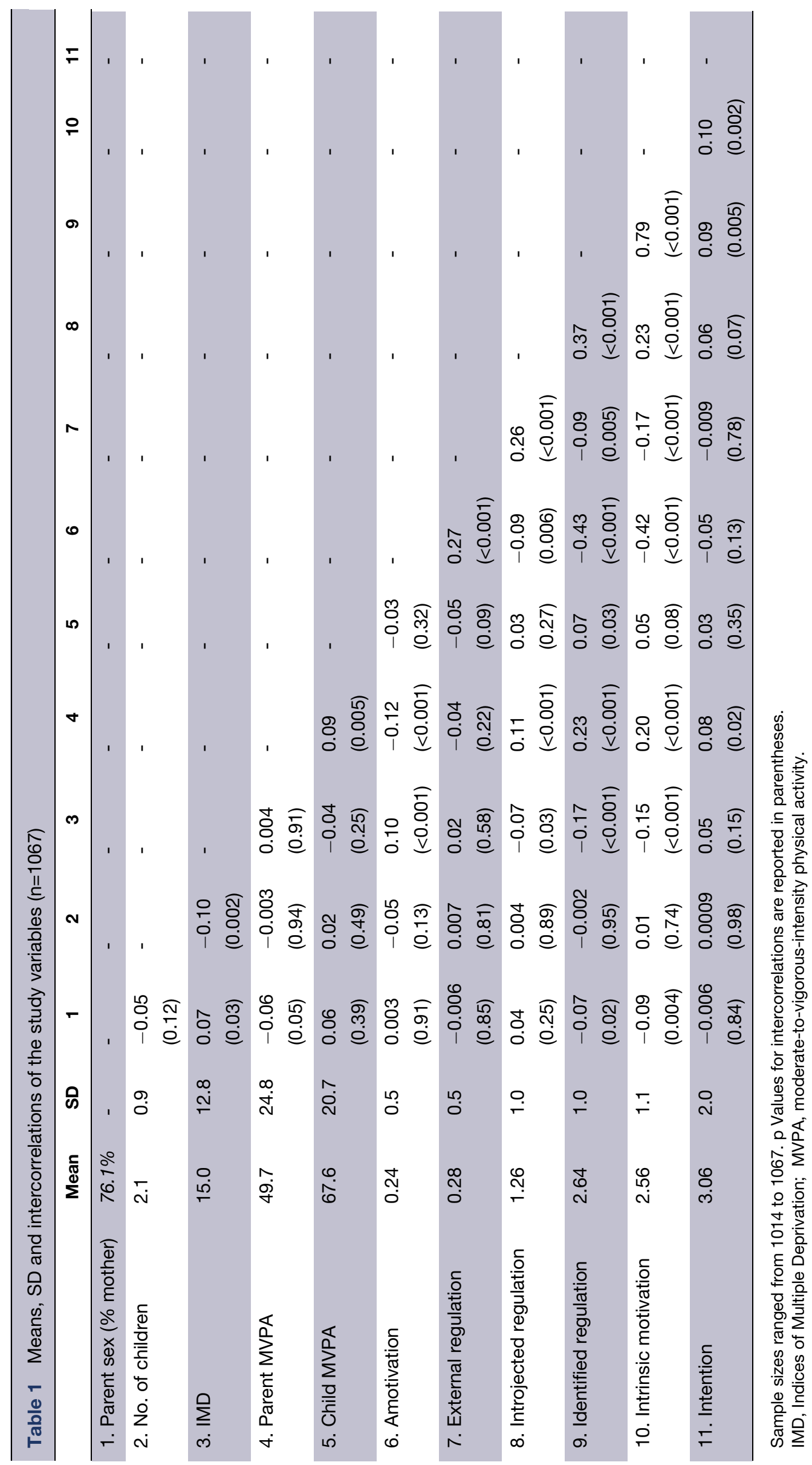


Table 2 Differences between included and excluded participants for each of the study variables

\begin{tabular}{|c|c|c|c|c|c|}
\hline & \multicolumn{2}{|c|}{ Included* } & \multicolumn{2}{|c|}{ Excluded } & \multirow[b]{2}{*}{$\mathbf{p}$} \\
\hline & $\mathbf{n}$ & Mean (SD) & $\mathbf{n}$ & Mean (SD) & \\
\hline Sex (\% mothers) & 911 & $74.5 \%(0.44)$ & 325 & $80.6 \%(0.40)$ & 0.03 \\
\hline Children in household & 911 & $2.15(0.94)$ & 130 & $1.95(1.00)$ & 0.02 \\
\hline IMD score & 911 & $13.96(11.93)$ & 257 & $18.54(15.09)$ & $<0.001$ \\
\hline Amotivation & 911 & $0.20(0.48)$ & 148 & $0.46(0.79)$ & $<0.001$ \\
\hline External regulation & 911 & $0.27(0.47)$ & 145 & $0.36(0.67)$ & 0.04 \\
\hline Introjected regulation & 911 & $1.27(1.01)$ & 151 & $1.16(1.07)$ & 0.23 \\
\hline Identified regulation & 911 & $2.69(0.96)$ & 144 & $2.32(1.08)$ & $<0.001$ \\
\hline Intrinsic motivation & 911 & $2.61(1.09)$ & 143 & $2.23(1.14)$ & $<0.001$ \\
\hline Intentions & 911 & $3.05(2.03)$ & 107 & $3.11(2.07)$ & 0.76 \\
\hline Parent MVPA & 911 & $49.98(24.42)$ & 251 & $48.75(26.10)$ & 0.49 \\
\hline Child MVPA & 895 & 67.65 (20.32) & 304 & $67.36(21.91)$ & 0.84 \\
\hline
\end{tabular}

*Included participants were parents with complete data for each of the study variables, child MVPA was treated as a separate variable. IMD, Indices of Multiple Deprivation; MVPA, moderate-to-vigorous-intensity physical activity.

Table 3 Linear regression analyses showing associations between parent exercise motivation, intention for family activity and their own physical activity

\begin{tabular}{|c|c|c|c|c|c|c|}
\hline \multirow[b]{2}{*}{ Predictor variable } & \multicolumn{3}{|c|}{ Unadjusted } & \multicolumn{3}{|c|}{ Fully adjusted } \\
\hline & Coeff $_{*}$ & $95 \% \mathrm{Cl}$ & p & Coeff. & $95 \% \mathrm{Cl}$ & p \\
\hline \multicolumn{7}{|l|}{ Personal factors } \\
\hline Parent sex & & & 0.05 & & & 0.15 \\
\hline Male & & Reference $\dagger$ & & & Reference & \\
\hline Female & -3.46 & -6.90 to -0.03 & & -2.60 & -6.13 to 0.93 & \\
\hline Number of children & -0.08 & -1.68 to 1.52 & 0.92 & -0.14 & -1.78 to 1.50 & 0.87 \\
\hline IMD score & -0.001 & -0.13 to 0.13 & 0.98 & 0.03 & -0.11 to 0.16 & 0.72 \\
\hline
\end{tabular}

Psychosocial factors

Motivation to exercise

$\begin{array}{lllllll}\text { Amotivation } & -5.53 & -8.30 \text { to }-2.75 & <0.001 & -0.53 & -4.16 \text { to } 3.11 & 0.78 \\ \text { External regulation } & -2.05 & -5.08 \text { to } 0.99 & 0.19 & -1.52 & -5.07 \text { to } 2.04 & 0.40 \\ \text { Introjected regulation } & 2.53 & 1.06 \text { to } 3.99 & 0.001 & 0.73 & -1.01 \text { to } 2.46 & 0.41 \\ \text { Identified regulation } & 5.76 & 4.28 \text { to } 7.25 & <0.001 & 6.08 & 3.27 \text { to } 8.89 & <0.001 \\ \text { Intrinsic motivation } & 4.44 & 3.10 \text { to } 5.78 & <0.001 & -0.35 & -2.65 \text { to } 1.95 & 0.77 \\ \text { Intention to engage in family- } & 0.91 & 0.16 \text { to } 1.67 & 0.02 & 0.67 & -0.08 \text { to } 1.43 & 0.08 \\ \text { based PA } & & & & & & \end{array}$

Sample sizes for the unadjusted analyses ranged from 968 to 1016, and for the adjusted analysis was 911 . All analyses adjusted for clustering at the school level.

*Regression coefficients are unstandardised.

$\dagger$ Male sex was used as a reference category, and given a value of zero, against which the effects of the female sex category were assessed.

IMD, Indices of Multiple Deprivation; PA, physical activity. 
Table 4 Linear regression analyses showing associations between parent exercise motivation, intention for family activity and their child's physical activity

\begin{tabular}{|c|c|c|c|c|c|c|}
\hline \multirow[b]{2}{*}{ Predictor variable } & \multicolumn{3}{|c|}{ Unadjusted } & \multicolumn{3}{|c|}{ Fully adjusted } \\
\hline & Coeff $*$ & $95 \% \mathrm{Cl}$ & $\mathbf{p}$ & Coeff. & $95 \% \mathrm{Cl}$ & p \\
\hline \multicolumn{7}{|l|}{ Personal factors } \\
\hline Parent sex & & & 0.07 & & & 0.02 \\
\hline Male & & Reference $\dagger$ & & & Reference & \\
\hline Female & 2.55 & -0.19 to 5.28 & & 3.32 & 0.47 to 6.16 & \\
\hline Number of children & 0.11 & -1.22 to 1.44 & 0.87 & 0.11 & -1.27 to 1.48 & 0.88 \\
\hline IMD score & -0.05 & -0.16 to 0.07 & 0.45 & -0.07 & -0.20 to 0.05 & 0.26 \\
\hline
\end{tabular}

Psychosocial factors

Motivation to exercise

Amotivation

External regulation

Introjected regulation

Identified regulation

Intrinsic motivation

Intention to engage in family-based PA

\section{$-0.92$}

$-2.16$

0.85

1.51

1.27

0.34

$\begin{array}{lll}-3.13 \text { to } 1.29 & 0.42 & 0.34 \\ -4.57 \text { to } 0.24 & 0.08 & -2.93 \\ -0.33 \text { to } 2.04 & 0.16 & 0.47 \\ 0.28 \text { to } 2.74 & 0.02 & 0.97 \\ 0.17 \text { to } 2.36 & 0.02 & 0.25 \\ -0.26 \text { to } 0.95 & 0.27 & 0.45\end{array}$

-2.59 to 3.27
-5.83 to -0.03
-0.94 to 1.89

0.82

0.05

0.51

-1.31 to 3.25

0.40

-1.63 to $2.12 \quad 0.80$

-0.17 to 1.07

0.15

*Regression coefficients are unstandardised.

$\dagger$ Male sex was used as a reference category, and given a value of zero, against which the effects of the female sex category were assessed. Sample sizes for the unadjusted analyses ranged from 986 to 1037, and for the adjusted analysis was 926 . All analyses adjusted for clustering at the school level.

IMD, Indices of Multiple Deprivation; PA, physical activity.

\section{DISCUSSION}

The data presented indicate that each unit increase in identified regulation was associated with six more minutes per day of MVPA for parents, whereas each unit increase in parental external regulation was weakly associated with almost 3 min per day less child MVPA. Although a 6-min per-day increase in MVPA for adults may seem small, if repeated daily across the week this would equate to an extra $42 \mathrm{~min}$ of MVPA, which is almost a third of the recommended guidelines. The 3-min per-day reduction in child MVPA is less compelling, because it accounts for only 5\% of their daily recommendation.

Previous research has shown that identified regulation is the dominant motivational factor associated with PA behaviour. ${ }^{21} 48$ Therefore, our finding among parents of young children concurs with research in the general adult population. Identified regulation is motivation rooted in the personal value placed on a behaviour, therefore, logically when a behaviour is accepted as personally important, the behaviour may be prioritised alongside other pressures on parents' time (eg, childcare). Intrinsic motivation was not associated with parent MVPA in the fully adjusted model, despite proposals in SDT that intrinsic motivation promotes the most positive motivational effects. ${ }^{20}$ One explanation suggests that if the target behaviour (eg, exercise) is not inherently interesting, identified regulation may be a more salient predictor of behaviour than intrinsic motivation, ${ }^{49}{ }^{50}$ which has been supported by several studies. ${ }^{21}{ }^{48}$ Participation in such activities is unlikely to be intrinsically driven for most individuals, but rather by what can be obtained from it (eg, health/fitness gains, losing weight). ${ }^{51}$ Even if parents of young children find PA enjoyable, this enjoyment may not be sufficient for parents to be active amid other parenting duties.

Parents' external regulation was weakly negatively associated with their child's MVPA, and not associated with their own MVPA. Similarly, introjected regulation was not associated with either child or adult MVPA. These findings suggest that family-based PA interventions which rely on strategies that promote parents' controlled motivation (eg, offering incentives, motivating through demand compliance or using guilt inducement) may be a poor investment of time and resources as they are unlikely to increase parents' MVPA, and may have a negative effect on child MVPA. Amotivation was not associated with MVPA for parents or children, consistent with previous literature. ${ }^{21}$ Empirically, it is difficult to distinguish amotivation from a lack of controlled or autonomous regulation. ${ }^{52}$ Additionally, it has been hypothesised that individuals could be autonomously motivated not to exercise, even 
Table 5 Linear regression analyses showing associations between parent exercise motivation, intention for family activity and their own accelerometer CPM

\begin{tabular}{|c|c|c|c|c|c|c|}
\hline \multirow[b]{2}{*}{ Predictor variable } & \multicolumn{3}{|c|}{ Unadjusted } & \multicolumn{3}{|c|}{ Fully adjusted } \\
\hline & Coeff $*$ & $95 \% \mathrm{Cl}$ & $\mathbf{p}$ & Coeff. & $95 \% \mathrm{Cl}$ & $\mathbf{p}$ \\
\hline \multicolumn{7}{|l|}{ Personal factors } \\
\hline Parent sex & & & 0.61 & & & 0.61 \\
\hline Male & & Reference $\dagger$ & & & Reference & \\
\hline Female & 53.3 & -148.8 to 255.3 & & 59.5 & -165.9 to 284.9 & \\
\hline Number of children & -55.9 & -151.3 to 39.6 & 0.25 & -65.6 & -169.9 to 38.8 & 0.22 \\
\hline IMD score & -2.6 & -9.9 to 4.7 & 0.48 & -3.0 & -11.3 to 5.2 & 0.47 \\
\hline
\end{tabular}

Psychosocial factors

Motivation to exercise

Amotivation

External regulation

Introjected regulation

Identified regulation

Intrinsic motivation

Intention to engage in family-based PA

$-69.3$

65.2

-233.6 to 95.0

0.41

$-78.6$

-310.6 to 153.5

0.51

47.1

-113.5 to 244.0

0.47

100.6

-125.7 to 326.9

0.38

42.9

-39.5 to 133.7

0.29

32.1

-78.6 to 142.7

0.57

36.7

-46.9 to 132.8

0.35

3.1

-174.8 to 181.0

0.97

$-4.9$

-43.6 to 117.0

0.37

19.3

-127.0 to 165.6

0.80

-50.1 to 40.4

0.83

$-5.9$

-54.0 to 42.2

0.81

*Regression coefficients are unstandardised.

$\dagger$ Male sex was used as a reference category, and given a value of zero, against which the effects of the female sex category were assessed. Sample sizes for the unadjusted analyses ranged from 968 to 1016, and for the adjusted analysis was 911 . All analyses adjusted for clustering at the school level.

CPM, counts per minute; IMD, Indices of Multiple Deprivation; PA, physical activity.

while perceiving some value in the behaviour. ${ }^{53} 54$ Therefore, amotivation may be confounding the associations between the other regulations in the multivariate analyses. ${ }^{21}$

As a measure of PA volume, accelerometer CPM were not associated with any motivation regulations for parents. One suggestion for this null finding is that CPM takes into account all incidental activity in the sedentary and light domains as well as more vigorous activity, whereas motivations are more likely to be associated with more conscious forms of activity like those accounted for by MVPA thresholds. However, parents' external regulation was negatively associated with children's accelerometer CPM, in agreement with the child MVPA data.

Reviews have highlighted that exercise intention is a consistent positive PA correlate in adults. ${ }^{4}{ }^{18}$ However, other studies have found no association between intention and $\mathrm{PA},{ }^{55}$ or found that medium-sized changes in intention resulted in only trivial changes in behaviour $(\mathrm{r}=0.06) \cdot{ }^{56}$ In the present study, intention to engage in family-based activity, rather than personal intention, was examined, but no association with MVPA was found. Although scores ranged from 0 to 7 , over $60 \%$ of parents intended to engage in regular family-based activity either twice or three times weekly, therefore, the lack of variation in intention may partially explain the absence of an association with MVPA. Although family-based activity intentions were measured, PA was measured separately for parents and children, meaning that no information was available on the quantity or quality of MVPA that was completed together as a family.

\section{Recommendations for future research}

Future research with families could combine accelerometry with activity diaries and/or global positioning system (GPS) data, ${ }^{57} 58$ in order to better understand the association between intention to engage in familybased activity if and when family PA occurs. To understand more about how parents are motivated, future research examining parents' motivations both for their own exercise and their children's activity levels is warranted. For parents who are active with their children, it would be fruitful to discover whether they are active together because they value the time, believe it is beneficial, feel that they should, or because they have no choice due to issues with childcare logistics or costs. Other suggestions include improving the intention measure by including different contexts (eg, weekday/ weekend day, active transportation), and examining links between motivation and other factors that might underpin family PA. 
Table 6 Linear regression analyses showing associations between parent exercise motivation, intention for family activity and their child's accelerometer CPM

\begin{tabular}{|c|c|c|c|c|c|c|}
\hline \multirow[b]{2}{*}{ Predictor variable } & \multicolumn{3}{|c|}{ Unadjusted } & \multicolumn{3}{|c|}{ Fully adjusted } \\
\hline & Coeff $*$ & $95 \% \mathrm{Cl}$ & $\mathbf{p}$ & Coeff. & $95 \% \mathrm{Cl}$ & $\mathbf{p}$ \\
\hline \multicolumn{7}{|l|}{ Personal factors } \\
\hline Parent sex & & & 0.02 & & & 0.01 \\
\hline Male & & Reference $\dagger$ & & & Reference & \\
\hline Female & 27.8 & 4.2 to 51.3 & & 31.6 & 7.6 to 55.6 & \\
\hline Number of children & 4.5 & -6.8 to 15.9 & 0.43 & 4.5 & -7.1 to 16.1 & 0.45 \\
\hline IMD score & -0.2 & -1.2 to 0.8 & 0.73 & -0.6 & -1.6 to 0.5 & 0.31 \\
\hline
\end{tabular}

Psychosocial factors

Motivation to exercise

Amotivation

External regulation

$-3.9$

-22.8 to 15.1

0.69

10.3

-14.4 to 35.1

0.41

$-19.2$

-40.1 to 1.6

0.07

$-29.3$

-53.8 to -4.7

0.02

Introjected regulation

10.7

0.4 to 20.9

0.04

11.0

-1.0 to 22.9

0.07

Identified regulation

8.1

Intrinsic motivation

8.1

-2.6 to 18.8

0.14

$-4.6$

-23.9 to 14.6

0.64

Intention to engage in family-based PA

4.1

-1.3 to 17.4

0.09

7.9

-7.9 to 23.8

0.33

-1.2 to 9.3

0.13

4.9

-0.4 to 10.1

0.07

* Regression coefficients are unstandardised.

$\dagger$ Male sex was used as a reference category, and given a value of zero, against which the effects of the female sex category were assessed. Sample sizes for the unadjusted analyses ranged from 986 to 1037 , and for the adjusted analysis was 926 . All analyses adjusted for clustering at the school level.

CPM, counts per minute; IMD, Indices of Multiple Deprivation; PA, physical activity.

\section{Strengths and limitations}

Strengths of this study included the large sample size with parent-child dyads and the objective measure of PA. However, the use of accelerometry limited our understanding of the types of PA in which parents and children engaged, and whether they engaged together or separately. The cross-sectional design of the study prevented the direction of the associations observed being assessed. The majority of parents met the recommended PA levels, suggesting this sample was not representative of the wider parent population, limiting the generalisability of the findings. PA levels may have been influenced by parents being informed that the study was measuring PA behaviour, and thus more active parents may have chosen to participate, resulting in self-selection bias. Additionally, 'wear effect' may have been a factor, where participants were more active than usual due to them being involved in the study and wearing an accelerometer, particularly in the first day of data collection. ${ }^{59}$ Participants included in the final analysis were generally similar to those excluded, however, minor differences were present in their reported motivation scores, deprivation, number of children and parent's sex, which may have led to missing data bias. Additionally, a total of 24 associations were tested, therefore it is possible that associations were affected by chance.

\section{CONCLUSION}

This study is the first to examine parents' autonomous and controlled motivation to exercise and intention to engage in family-based activity in relation to both parent and child objectively measured MVPA. The results demonstrate that despite the challenges and time constraints of being a parent of a young child, the associations between motivation regulations and PA are similar in pattern to findings from the general adult population. Parents' motivation which stemmed from a personal valuing of exercise was associated with greater parent MVPA, whereas motivation based on pressure and coercion was negatively associated with their child's CPM and MVPA, although this association was weak, and so may be due to chance. Intention to engage in family-based PA was not associated with parent or child MVPA. These results highlight the potential benefits of focusing future family-based PA interventions on helping parents identify with personally meaningful or valuable benefits of exercise while avoiding the use of external contingencies to motivate behaviour.

Acknowledgements We would like to thank the participants for taking part in the study. We would also like to thank the members of the B-ProAct $1 v$ team who are not authors of this paper. 
Contributors RJ, SJS, JLT and DAL were involved in the design of the BProact1v study and in seeking funding for it. RJ and $\mathrm{JZ}$ were responsible for the B-Proact1v study conduct and managing data collection. ESM performed all analyses. ESM wrote the first draft of the paper and coordinated contributions from other co-authors. All authors made critical comments on drafts of the paper. All authors read and approved the final manuscript.

Funding Data presented in this paper were funded by British Heart Foundation project grants (ref PG/11/51/28986 and SP/14/4/31123). The funder had no involvement in data analysis, data interpretation, or writing of the paper.

\section{Competing interests None declared.}

Provenance and peer review Not commissioned; externally peer reviewed.

Open Access This is an Open Access article distributed in accordance with the terms of the Creative Commons Attribution (CC BY 4.0) license, which permits others to distribute, remix, adapt and build upon this work, for commercial use, provided the original work is properly cited. See: http:// creativecommons.org/licenses/by/4.0/

(C) Article author(s) (or their employer(s) unless otherwise stated in the text of the article) 2017. All rights reserved. No commercial use is permitted unless otherwise expressly granted.

\section{REFERENCES}

1. World Health Organization. Global recommendations on physical activity for health. Geneva, Switzerland: World Health Organization, 2010

2. Health. Social care information centre. Health survey for England 2012: Health, social care and lifestyles. London, England: Health and Social Care Information Centre, 2013.

3. The NHS Information Centre. Health Survey for England 2008: Physical Activity and Fitness. London, England: The NHS Information Centre, 2009.

4. Bauman AE, Reis RS, Sallis JF, et al; Lancet Physical Activity Series Working Group. Correlates of physical activity: why are some people physically active and others not? Lancet 2012;380:258-71.

5. Brown WJ, Trost SG. Life transitions and changing physical activity patterns in young women. Am J Prev Med 2003;25:140-3.

6. Hull EE, Rofey DL, Robertson RJ, et al. Influence of marriage and parenthood on physical activity: a 2-year prospective analysis. $J$ Phys Act Health 2010;7:577-83.

7. Brown PR, Brown WJ, Miller YD, et al. Perceived constraints and social support for active leisure among mothers with young children. Leis Sci 2001;23:131-44.

8. Deflandre A, Antonini PR, Lorant J. Perceived benefits and barriers to physical activity among children, adolescents and adults. Int $J$ Sport Psychol 2004;35:23-36.

9. Aldous J, Mulligan GM, Bjarnason T. Fathering over time: What makes the difference? J Marriage Fam 1998;60:809-820.

10. Baxter J, Hewitt B, Haynes M. Life course transitions and housework: Marriage, Parenthood, and Time on Housework. J Marriage 2008;70:259-72.

11. Lewis $B$, Ridge $D$. Mothers reframing physical activity: family oriented Politicism, transgression and contested expertise in Australia. Soc Sci Med 2005;60:2295-306.

12. Jago R, Sebire SJ, Wood L, et al. Associations between objectively assessed child and parental physical activity: a cross-sectional study of families with 5-6 year old children. BMC Public Health 2014;14:655.

13. Jago R, Fox KR, Page AS, et al. Parent and child physical activity and sedentary time: Do active parents foster active children? BMC Public Health 2010;10:194.

14. Davison KK, Cutting TM, Birch LL. Parents' activity-related parenting practices predict girls' physical activity. Med Sci Sports Exerc 2003;35:1589-95.

15. Gustafson SL, Rhodes RE. Parental correlates of physical activity in children and early adolescents. Sports Med 2006;36:79-97.

16. Thompson JL, Jago R, Brockman R, et al. Physically active families de-bunking the myth? A qualitative study of family participation in physical activity. Child: Care, Health and Development 2010;36:265-74.

17. Jago R, Fox KR, Page AS, et al. Parent and child physical activity and sedentary time: do active parents foster active children? BMC Public Health 2010;10:194.

18. Trost SG, Owen N, Bauman AE, et al. Correlates of adults' participation in physical activity: review and update. Med Sci Sports Exerc 2002;34:1996-2001.
19. Deci EL, Ryan RM. The "what" and "why" of goal pursuits: human needs and the self-determination of behavior. Psychol Inq 2000;11:227-68.

20. Ryan RM, Deci EL. Intrinsic and extrinsic motivations: Classic definitions and new directions. Contemp Educ Psychol 2000;25:54-67.

21. Teixeira PJ, Carraça EV, Markland D, et al. Exercise, physical activity, and self-determination theory: a systematic review. Int $J$ Behav Nutr Phys Act 2012;9:78.

22. Sebire SJ, Standage M, Vansteenkiste M. Predicting objectively assessed physical activity from the content and regulation of exercise goals: evidence for a mediational model. J Sport Exerc Psychol 2011;33:175-97.

23. Standage M, Sebire SJ, Loney T. Does exercise motivation predict engagement in objectively assessed bouts of Moderate-Intensity exercise?: A Self-Determination theory perspective. Journal of Sport and Exercise Psychology 2008;30:337-52.

24. Daley AJ, Duda JL. Self-determination, stage of readiness to change for exercise, and frequency of physical activity in young people. Eur $J$ Sport Sci 2006:6:231-43.

25. Thøgersen-Ntoumani $\mathrm{C}$, Ntoumanis $\mathrm{N}$. The role of self-determined motivation in the understanding of exercise-related behaviours, cognitions and physical self-evaluations. J Sports Sci 2006;24:393-404.

26. Wilson PM, Rodgers WM, Fraser SN. Examining the psychometric properties of the behavioral regulation in exercise questionnaire. Meas Phys Educ Exerc Sci 2002;6:1-21.

27. Hamilton K, Cox S, White KM. Testing a model of physical activity among mothers and fathers of young children: Integrating SelfDetermined motivation, Planning, and the Theory of Planned Behavior. Journal of Sport and Exercise Psychology 2012;34:124-45.

28. Hagger MS, Chatzisarantis NLD. Integrating the theory of planned behaviour and self-determination theory in health behaviour: A metaanalysis. Br J Health Psychol 2009;14:275-302.

29. Hagger MS, Hardcastle SJ, Chater A, et al. Autonomous and controlled motivational regulations for multiple health-related behaviors: between- and within-participants analyses. Health Psychol Behav Med 2014;2:565-601.

30. Jago R, Thompson JL, Sebire SJ, et al. Cross-sectional associations between the screen-time of parents and young children: differences by parent and child gender and day of the week. Int J Behav Nutr Phys Act 2014;11:54

31. Jago R, Wood L, Zahra J, et al. Parental control, nurturance, selfefficacy, and screen viewing among 5- to 6-year-old children: a cross-sectional mediation analysis to inform potential behavior change strategies. Child Obes 2015;11:139-47.

32. Zahra J, Jago R, Sebire SJ. Associations between parenting partners' objectively-assessed physical activity and Body Mass Index: A cross-sectional study. Prev Med Rep 2015;2:473-7.

33. Sebire SJ, Jago R, Wood L, et al. Examining a conceptual model of parental nurturance, parenting practices and physical activity among 5-6 year olds. Soc Sci Med 2016;148:18-24.

34. Wood L, Jago R, Sebire SJ, et al. Sedentary time among spouses: a cross-sectional study exploring associations in sedentary time and behaviour in parents of 5 and 6 year old children. BMC Res Notes 2015;8:787.

35. Jago R, Bailey R. Ethics and paediatric exercise science: issues and making a submission to a local ethics and research committee. $J$ Sports Sci 2001;19:527-35.

36. Lee JA, Williams SM, Brown DD, et al. Concurrent validation of the actigraph gt $3 \mathrm{x}+$, Polar Active accelerometer, Omron $\mathrm{HJ}-720$ and Yamax Digiwalker SW-701 pedometer step counts in lab-based and free-living settings. J Sports Sci 2015;33:991-1000.

37. Vanhelst J, Mikulovic J, Bui-Xuan G, et al. Comparison of two ActiGraph accelerometer generations in the assessment of physical activity in free living conditions. BMC Res Notes 2012;5:187.

38. Tudor-Locke C, Barreira TV, Schuna JM. Comparison of step outputs for waist and wrist accelerometer attachment sites. Med Sci Sports Exerc 2015;47:839-42.

39. Mattocks C, Ness A, Leary S, et al. Use of accelerometers in a large field-based study of children: protocols, design issues, and effects on precision. J Phys Act Health 2008;5(suppl 1):S98-111.

40. Evenson KR, Catellier DJ, Gill K, et al. Calibration of two objective measures of physical activity for children. J Sports Sci 2008;26:1557-65.

41. Troiano RP, Berrigan D, Dodd KW, et al. Physical activity in the United States measured by accelerometer. Med Sci Sports Exerc 2008;40:181-8.

42. Markland $D$, Tobin $V$. A modification to the behavioural regulation in exercise questionnaire to include an assessment of amotivation. Journal of Sport and Exercise Psychology 2004;26:191-6. 
43. Rhodes RE, Blanchard CM, Matheson DH, et al. Disentangling motivation, intention, and planning in the physical activity domain. Psychol Sport Exerc 2006;7:15-27.

44. Rhodes RE, Naylor PJ, McKay HA. Pilot study of a family physical activity planning intervention among parents and their children. $J$ Behav Med 2010;33:91-100.

45. Cerin E, Leslie E, Owen N. Explaining socio-economic status differences in walking for transport: an ecological analysis of individual, social and environmental factors. Soc Sci Med 2009;68:1013-20.

46. STATA. StataCorp. Version 12. College Station: TX. 2011.

47. Bull FC, the Expert Working Groups. Physical Activity Guidelines in the UK: Review and Recommendations. School of Sport, Exercise and Health Sciences: Loughborough University, 2010.

48. Wilson PM, Sabiston CM, Mack DE, et al. On the nature and function of scoring protocols used in exercise motivation research: An empirical study of the behavioral regulation in exercise questionnaire. Psychol Sport Exerc 2012;13:614-22.

49. Ryan RM. Psychological needs and the facilitation of integrative processes. J Pers 1995;63:397-427.

50. Vallerand RJ. A hierarchical model of intrinsic and extrinsic motivation in sport and exercise. In: Roberts GC, ed. Advances in Motivation in Sport and Exercise. Champaign, IL: Human Kinetics, 2001:263-319.

51. Standage M, Ryan RM. Self-Determination Theory and Exercise Motivation: Facilitating Self-Regulatory Processes to Support and Maintain Health and Well-being. In: Roberts GC, Treasure DC, eds. Advances in Motivation in Sport and Exercise. $3^{\text {rd }}$ ed. Champaign, USA: Human Kinetics, 2012:233-70.
52. Ingledew DK, Markland D. The role of motives in exercise participation. Psychol Health 2008;23:807-28.

53. Ryan RM, Williams GC, Patrick H, et al. Self-determination theory and physical activity: The dynamics of motivation in development and wellness. Hellenic Journal of Psychology 2009;6:107-24.

54. Vansteenkiste M, Niemiec CP, Soenens B. The development of five mini-theories of self-determination theory: an historical overview, emerging trends, and future directions. In: Urdan TC, Karabenick SA eds. The Decade Ahead: Theoretical Perspectives on Motivation and Achievement (Advances in Motivation and Achievement). 16: Emerald Group Publishing Limited, 2010:105-65.

55. Poobalan AS, Aucott LS, Clarke A, et al. Physical activity attitudes, intentions and behaviour among $18-25$ year olds: a mixed method study. BMC Public Health 2012;12:640.

56. Rhodes RE, Dickau L. Meta-analysis of experimental evidence for the intention-behavior relationship in the physical activity domain. Health Psychol 2012;31:724-7.

57. Wheeler BW, Cooper AR, Page AS, et al. Greenspace and children's physical activity: a GPS/GIS analysis of the PEACH project. Prev Med 2010;51:148-52.

58. Cooper AR, Page AS, Wheeler BW, et al. Patterns of GPS measured time outdoors after school and objective physical activity in english children: the PEACH project. Int J Behav Nutr Phys Act 2010;7:31-9.

59. MacMillan F, Kirk A, Diabetes UK. Patterns of physical activity and the effect of accelerometer wear on physical activity participation in people with type 2 diabetes. CARE A scholary journal for nursing, midwifery \& allied \& community health 2010;3:6-22. 